\title{
Therapeutic Responses to Chemotherapy or Immunotherapy by Molecular Subtype in Bladder Cancer Patients: A Meta-Analysis and Systematic Review
}

\author{
Shunde Wang \\ The Second Affiliated Hospital of Chongqing Medical University \\ Xiaoyu Yuan \\ The Second Affiliated Hospital of Chongqing Medical University \\ Chengguo Ge \\ The Second Affiliated Hospital of Chongqing Medical University \\ Junyong Zhang ( $\square$ zhangmachine@cqmu.edu.cn ) \\ The Second Affiliated Hospital of Chongqing Medical University \\ Zhongjie Shen \\ The Second Affiliated Hospital of Chongqing Medical University \\ Jiaming Zhao \\ The Second Affiliated Hospital of Chongqing Medical University \\ Baishu Zheng \\ The Second Affiliated Hospital of Chongqing Medical University
}

\section{Research Article}

Keywords: Bladder cancer, Molecular subtype, Therapeutic response, Chemotherapy, Immunotherapy.

Posted Date: March 15th, 2021

DOI: https://doi.org/10.21203/rs.3.rs-290062/v1

License: (c) (i) This work is licensed under a Creative Commons Attribution 4.0 International License. Read Full License 


\section{Abstract}

Background Bladder cancer (BC) is a heterogeneous disease characterized by high recurrence and a poor prognosis. Molecular subtypes of $\mathrm{BC}$ portend personalized and precision medicine. However, whether there is a difference in therapeutic response to chemotherapy or immunotherapy between different molecular subtypes of $\mathrm{BC}$ has not been systematically evaluated.

Methods A comprehensive literature search was performed up to October 2020. Consensus clusters 1 (CC1), CC2 and CC3 molecular subtypes were defined according to the heterogeneity and similarity of BC molecular subtypes from published studies to perform meta-analysis. Pooled odds ratios (ORs) with $95 \%$ confidence intervals (Cls) were used to assess the therapeutic response, and a fixed- or random-effects model was used according to the existence of heterogeneity.

Results Eight studies involving 1463 patients were included in this research. For immunotherapy, CC3 showed the highest respond rate (CC3 vs CC1: OR 0.52, $\mathrm{Cl}[0.34-0.78], \mathrm{P}=0.002$. CC3 vs CC2: OR 0.42, $\mathrm{Cl}[0.28-0.62], \mathrm{P}<0.0001)$, which was mainly reflected in the highest response rate to atezolizumab (CC3 vs CC1: OR 0.47, $\mathrm{Cl}[0.29-0.75], \mathrm{P}=0.002$. CC3 vs CC2: OR 0.38, $\mathrm{Cl}[0.24-0.59], \mathrm{P}<0.0001)$, and the response rates to nivolumab showed no advantage over $\mathrm{CC} 1$ and CC2. No difference in response to the two immunotherapies between $\mathrm{CC} 1$ and CC2. For chemotherapy, CC3 had the lowest response rate to the overall chemotherapy (CC3 vs CC1: OR 2.28, Cl [1.39-3.74], $\mathrm{P}=0.001$. CC3 vs CC2: OR $=2.25,95 \% \mathrm{Cl} 1.34-3.76, \mathrm{P}=0.002)$. Compared with CC2, CC3 responded poorly to both neo-adjuvant chemotherapy (NAC) (OR 1.93, $\mathrm{Cl}$ [1.09-3.41], $\mathrm{P}=0.02)$ and chemoradiation therapy $(\mathrm{CRT})(\mathrm{OR} 4.53, \mathrm{Cl}$ [1.26-16.27], $\mathrm{P}=0.02)$. Compared with CC1, CC3 only showed a poorer response to CRT (OR 6.07, Cl [1.87-19.71], P=0.003), and no difference in NAC. No difference between CC1 and CC2 subtypes in the response rates to NAC and CRT.

Conclusions Our study suggested that molecular classifications are important predictors of cancer treatment outcomes of BC patients and could identify subgroup patients who are most likely to benefit from specific cancer treatments.

\section{Introduction}

Bladder cancer (BC) is a heterogeneous disease characterized by high recurrence and poor prognosis, and the responses to standard treatments are quite different in patients with $\mathrm{BC}[1,2]$, such as radical cystectomy and chemotherapy based on cisplatinum. The advent of immune checkpoint inhibitors has completely transformed the treatment landscape of $\mathrm{BC}$ enabling to expand the treatment strategies[3]. The management decisions of $\mathrm{BC}$ depend on its pathologic features: tumor stage and grade, surgical margin status, histology and lymph node status[4]. However, probably due to BC molecular heterogeneity, $\mathrm{BC}$ patients with the same tumor stage or grade may have varied prognoses or responses to the same therapeutic strategy[5].

Benefiting from the rapid development of genomics, the National Cancer Institute proposed the concept of the molecular subtyping of cancers in 1999, which aimed to transform the morphological classification of $\mathrm{BC}$ into molecular classification through gene analysis technology to provide more accurate guidance for precise treatment.

To date, several molecular classifications have been defined[6-11], including Baylor, University of North Carolina, MD Anderson Cancer Center, The Cancer Genome Atlas, Cartes d'Identité des Tumeurs -Curie and Lund. Every single classification system is different from the others. However, the heterogeneity among these classification methods has somehow impeded the application value of BC molecular classification. Therefore, we conducted this meta-analysis and systematic review to elaborate the response of different molecular subtypes of BC to chemotherapy or immunotherapy.

\section{Methods}

\subsection{Search strategy}

A comprehensive literature search was performed in the PubMed, Cochrane Library, Scopus, EMBASE, MEDLINE, Web of Science, CBM and CNKI by two independent authors according to the guidelines of Preferred Reporting Items for Systematic Review and Meta-Analysis (PRISMA)[12], without language and publication time limitations, up to October 2020. We created a detailed search strategy for PubMed and Cochrane Library (Table 1), and similar search strategies were carried out in other databases. We also checked the references of the relevant articles to search for potential studies. The international prospective register of systematic reviews (PROSPERO) search showed no analogical registered or published reviews. The protocol for this meta-analysis was registered in PROSPERO (CRD42021227927).

\subsection{Inclusion criteria}

We set the inclusion criteria according to the study design, namely, randomized controlled trials (RCTs) or retrospective studies, which contained the patient cohort, intervention strategy, comparator, and outcome. Patients with a specific molecular subtype of BC and treated with a particular treatment were compared with patients with another molecular subtype in terms of response to the same cancer treatment. These kinds of studies were considered relevant to our meta-analysis.

\subsection{Exclusion criteria}

Conference abstracts, letters, comments, meta-analyses, reviews, and case reports were excluded. Duplicated publications or studies with ambiguous molecular subtypes were also excluded. If more than one study of the same cohort existed, only the most informative and latest article was included.

\subsection{Data extraction}


Two independent researchers performed data extraction using a previously created normalized data extraction form. Any inconsistencies will be solved with the help of the third researcher, and a final decision will be made after discussion. The extracted information included first author details, publication year, trial design, number of molecular classified patients, tumor stage, age, classification method, detailed molecular subtypes, details of the treatment, definition of response to cancer treatment, and follow-up period. If any insufficient or missing data were identified, we contacted the original authors to request them.

\subsection{Definition of $\mathrm{BC}$ molecular subtypes}

According to the heterogeneity and similarity in different molecular classification systems of BC that were mentioned in the research of Aine et al[13] which integrated and reclassified the published classification systems of BC, and the consensus on molecular classification of bladder cancer published in 2019[5], we defined three molecular subtypes of BC as consensus clusters 1 (CC1), CC2 and CC3, which were used in this meta-study (Fig. 1). Among them, the CC1 subtypes included basal, basal cluster III-IV, claudin-low, basal 1 and 2, class 4, and genomically unstable (GU). The CC2 subtypes included luminal, luminal cluster I, luminal 1, luminal-papillary, class 1 and 2, and squamous cell cancer-like (SCCL). The CC3 subtypes included p53-like, luminal cluster II, luminal, luminal-infiltrated, luminal 2, class 3, neuronal, and urobasal (Uro).

\subsection{Statistical analysis}

Review Manager 5.4 software was used to execute statistical analysis. We used odds ratios (ORs) and $95 \%$ confidence intervals (95\% Cls) to calculate the response to different cancer treatments in the CC1, CC2 and CC3 subtypes. Heterogeneity between included studies was examined by Cochran's Q test and $\mathrm{I}^{2}$ statistic: $\left.\right|^{2}<50 \%$ signified homogeneity, while $\mathrm{I}^{2}>50 \%$ indicated obvious heterogeneity. We performed a fixed-effects model if $\mathrm{I}^{2}<50 \%$ and/or $\mathrm{P}<0.01$, and a meta-analysis was conducted if possible. Otherwise, we employed a random-effects model if $\mathrm{I}^{2}>50 \%$ and/or $\mathrm{P}>0.01$, and subgroup analysis was performed to check the sources of such heterogeneity. Sensitivity analysis was performed by excluding single studies one by one to examine the stability and reliability. Funnel plots were used to assess publication bias.

\subsection{Quality assessment}

The risk of bias (RoB) assessment of all included RCTs was performed according to the Cochrane Collaboration, which consists of the following items: selection bias (random sequence generation, allocation concealment), performance bias (blinding of participants and personnel), detection bias (blinding of outcome assessment), attrition bias (incomplete outcome data), reporting bias (selective reporting) and other bias. The Newcastle-Ottawa Scale (NOS) quality scale was used to assess the quality of retrospective studies[14]. All quality assessments were conducted by two researchers independently.

\section{Results}

\subsection{Literature search process}

A total of 3359 studies were screened after the exclusion of duplicates. The study screening process is shown in Fig. 2 . A total of 3319 studies were excluded after title and abstract review: books and documents $(n=7)$, case reports $(n=50)$, meta-analyses $(n=17)$, reviews and systematic reviews $(n=910)$, and nonrelevant studies according to the inclusion criteria $(n=2335)$. Forty studies remained for full-text screening, and 32 studies were excluded because of unclear or unavailable data between BC molecular subtypes and therapeutic response. Finally, eight studies were included in this meta-analysis.

\subsection{Characteristics of the included studies}

Table 2 summarizes the characteristics of the included studies. Immunohistochemistry (IHC) and gene expression (GE) were used as molecular classification methods in 1[15] and 7[7,16-21] studies, respectively. Two studies were designed prospectively[16,17], and 6 were retrospectively reviewed[7,15,18-21]. All studies were published between 2014 and 2019. The patient cohort size ranged from 73 to 298 . Four cohorts received chemotherapy[7.18,19.21], and 4 cohorts received immunotherapy[15-17'20].

\subsection{Quality assessment}

The RoB tool suggested by the Cochrane Collaboration was used to evaluate the quality of the included RCTs (Fig. 3). Two studies[15'20] described how the random sequence was performed, and none of the RCTs described the allocation hiding or blinding method. No incomplete or selective results were reported. Quality assessments of retrospective studies[7,16-19.21] were conducted according to the NOS quality scale (Table 3).

\subsection{Molecular classification system and oncological outcomes}

Six studies reported the oncological results of patients classified into CC1, CC2 and CC3 molecular subtypes. Overall survival (OS), disease-specific survival (DSS), and cancer-specific mortality (CSM) were assessed in 6, 3, and 1 study, respectively. Two studies reported the best OS for the CC3 subtype with immunotherapy[16,17], while the other two studies reported the worst OS for the CC3 subtype with chemotherapy[721]. Three studies reported the best OS for the CC2 subtype with chemotherapy[7-18.21]. One study reported worst DSS for CC3 subtype[7]. One study reported best DSS for CC2 subtype[18]. Only one study reported CSMs of 16\% (95\% Cl: 12-20\%), 23\% (95\% Cl: 20-26\%), and 24\% (95\% Cl: 18-30\%) for CC1, CC2, and CC3, respectively[19].

\subsection{Meta-analysis}

\subsubsection{Therapeutic responses to immunotherapy.}


Four studies ( $n=835)$ were included in this meta-analysis to compare different response rates to immunotherapy in the CC1, CC2 and CC3 subtypes[15-17.20]. There was no significant difference in the response rate between the CC1 and CC2 subtypes (OR=1.25, 95\%: 0.81-1.94, $P=0.32$. Fig. 4 A), the Q- and $\mathrm{I}^{2}$ tests showed no significant heterogeneity $\left(I^{2}=0 \%, P=0.68\right)$. The pooled OR indicated a higher response rate in the CC3 subtype than in the CC1 subtype (OR=0.52, $95 \% \mathrm{Cl}: 0.34-0.78, P=0.002$. Fig. $4 \mathrm{~B})$, without any heterogeneity $\left(\mathrm{I}^{2}=0 \%, P=0.65\right)$. The CC3 subtype also had a higher response rate than the CC2 subtype (OR=0.42, 95\% Cl: $0.28-0.62, P<0.0001$. Fig. $4 \mathrm{C}$ ), and the $\mathrm{Q}$ - and $\mathrm{I}^{2}$ tests showed no significant heterogeneity $\left(\mathrm{I}^{2}=0 \%, P=0.42\right)$.

\subsubsection{Subgroup analysis stratified by immunotherapeutic regimens.}

Subgroup analysis was conducted based on two immunotherapeutic regimens: nivolumab, atezolizumab. The pooled OR showed no statistically difference of response rates of nivolumab $(\mathrm{OR}=1.23,95 \% \mathrm{Cl}$ : 0.50-3.00, $P=0.65)$ and atezolizumab $\left(\mathrm{OR}=1.26,95 \% \mathrm{Cl}: 0.76-2.08, P=0.37, \mathrm{I}^{2}=0 \%\right)$ between $\mathrm{CC} 1$ and $\mathrm{CC} 2$ subtypes (Fig. 5 A). The CC3 subtype had the highest response rates to atezolizumab than $\mathrm{CC} 1$ subtype $\left(\mathrm{OR}=0.47,95 \% \mathrm{Cl}: 0.29-0.75, P=0.002, I^{2}=0 \%\right.$. Fig. $\mathbf{5}$ B) and CC2 subtype (OR=0.38, 95\% Cl: 0.24-0.59, $P<0.0001, \mathrm{l}^{2}=1 \%$. Fig. $\left.5 \mathrm{C}\right)$, but had no significant difference of response rates of nivolumab compared with CC1 subtype (OR=0.73, 95\% Cl:0.30-1.74, $P=0.47)$ and $\mathrm{CC} 2$ subtype (OR=0.59, 95\% $\mathrm{Cl}: 0.25-1.40, P=0.23)$. The publishing bias were limited.

\subsubsection{Therapeutic responses to chemotherapy.}

Four studies $(n=628)$ were included in this analysis to compare different response rates to chemotherapy in the CC1, CC2 and CC3 subtypes[7.18.19.21]. The pooled OR indicated no significant difference in the response rates between the CC1 and CC2 subtypes (OR=0.98, 95\%: 0.68-1.44, $P=0.92$. Fig. 6 A), the Q- and $\mathrm{I}^{2}$ tests showed no significant heterogeneity $\left(\mathrm{I}^{2}=0 \%, P=0.72\right)$. The $\mathrm{CC} 1$ subtype had a higher response rate than the CC3 subtype (OR=2.28, 95\% $\mathrm{Cl}$ : $1.39-3.74$, $P=0.001$. Fig. $6 \mathrm{~B})$, the $\mathrm{Q}$ - and $\mathrm{I}^{2}$ tests showed no significant heterogeneity $\left(\mathrm{I}^{2}=42 \%, P=0.16\right)$. The pooled OR also indicated a higher therapeutic response to chemotherapy in the $\mathrm{CC} 2$ subtype (OR=2.25, 95\% Cl: $1.34-3.76, P=0.002$. Fig. $6 \mathrm{C})$, with no significant heterogeneity $\left(I^{2}=36 \%, P=0.19\right)$.

\subsubsection{Subgroup analysis stratified by chemotherapeutic regimens.}

Subgroup analysis was performed according to two chemotherapeutic regimens: neo-adjuvant chemotherapy (NAC), chemoradiation therapy (CRT). The pooled OR demonstrated no significant difference of response rates of NAC (OR=0.92, 95\% Cl: 0.62-1.37, $\left.P=0.68, \mathrm{I}^{2}=0 \%\right)$ or $\mathrm{CRT}(\mathrm{OR}=1.34,95 \% \mathrm{Cl}$ : $0.56-3.19$, $P=0.51$ ) between $\mathrm{CC} 1$ and $\mathrm{CC} 2$ subtypes (Fig. $7 \mathrm{~A}$ ). The CC1 subtype had a higher response rate to $\mathrm{CRT}(\mathrm{OR}=6.07,95 \% \mathrm{Cl}: 1.87-19.71, P=0.003)$, but had no significant difference of response rate of NAC (OR=1.73, 95\% Cl: 0.99-3.04, $\left.P=0.06, \mathrm{I}^{2}=0 \%\right)$ compared with CC3 subtype (Fig. 7 B). The CC2 subtype had a higher response rates to both NAC (OR=1.93, 95\% Cl: 1.09-3.41, $\left.P=0.02, \mathrm{I}^{2}=36 \%\right)$ and $\mathrm{CRT}(\mathrm{OR}=4.53,95 \% \mathrm{Cl}: 1.26-16.27, P=0.02)$ than $\mathrm{CC} 3$ subtype (Fig. $7 \mathrm{C}$ ). The publishing bias were limited

\section{Discussion}

Studies had confirmed that referring to the results of GE and ICH of specimens could significantly improve the accuracy of the prediction model for BC prognosis [22]. Consistently, our meta-analysis and systematic review showed that among the 23 molecular subtypes in 8 published studies, different molecular subtypes did have significantly different responses to chemotherapy or immunotherapy.

Our research showed that the CC3 subtypes (including p53-like, luminal cluster II, luminal, luminal-infiltrated, luminal 2, class 3, neuronal, and Uro) had the worst response to NAC or CRT but the best response to immunotherapy of atezolizumab. Published studies reported that the p53-like subtype was significantly resistant to chemotherapy[23-26], which would be one of the reasons why the CC3 subtype was resistant to chemotherapy. On the other hand, there was no significant difference between the CC1 subtype (including basal, basal cluster III-IV, claudin-low, basal 1 and 2, class 4 , and GU) and the CC2 subtype (including luminal, luminal cluster I, luminal 1, luminal-papillary, class 1 and 2, and SCCL) in response to chemotherapy or immunotherapy. Among patients receiving chemotherapy, the effective response rate of patients with the CC1 and CC2 subtypes was significantly higher than that of patients with the CC3 subtype [5,19,27]. The CC3 subtype was confirmed to show chemotherapy resistance in our study, which meant that chemotherapy was not suitable for $\mathrm{BC}$ patients of $\mathrm{CC} 3$ but those of $\mathrm{CC} 1$ and $\mathrm{CC} 2[7 \cdot 21 \cdot 27]$. Thus, molecular classification of BC helped to identify patients who benefited the most from chemotherapy while to protect patients from chemotherapy-related adverse reactions and ineffective chemotherapy that delayed effective treatment.

In recent years, immunotherapy had been proven to be an effective strategy for the treatment of advanced and metastatic BC, whether as a monotherapy or in combination with other treatments[28.29]. However, even this promising therapy had an overall response rate of only $10 \%$ to $30 \%[30]$, which indicated the importance of accurately identifying patients who would benefit from these novel drugs[31]. According to reports, patients with advanced BC who had received chemotherapy showed a better response to atezolizumab[15-17.20], and the efficacy rate could be increased $34 \%$ to $100 \%$. This phenomenon supported our result that the CC3 subtype had the best response to immunotherapy but chemotherapy.

In 8 studies we finally included, 6 were retrospective studies, and the molecular classification criteria for BC used in each study were different. Therefore, we used a compromise method to define three molecular subtypes (CC1, CC2, and CC3 subtypes) for this meta-analysis referring to the published literatures. This might induce overlap of certain subtypes from different classification systems, which led to the bias of our research to some extent. In addition, due to the disunity of the oncology statistical results, such as OS (overall survival), CSM (cancer specific mortality), or DSS (Disease Specific Survival), in the articles we included, a unified meta-analysis for oncological outcomes was not possible to operate. Therefore, we had to roughly compare the response rates of different molecular types of BC to different treatments only. All these above affected the accuracy of this research on the molecular subtypes of BC in guiding clinical treatment decisions. Kamoun et al reported a consensus[5] in Eur Urol 2020 on the six subtypes of the molecular classification of muscle infiltrating BC and predicted potential treatment responses, which provided common guidance for future research. Even so, a large number of well-designed RCTs were still 
needed to reach a consensus on molecular classification, to accurately assess the prognostic value of molecular subtypes, and to provide references for clinicians to make treatment decisions for BC patients.

\section{Conclusions}

Our study suggested that the molecular classification of BC was a strong predictor of therapeutic response. Genotyping and transcriptional profiling would enhance the precision of treatment of BC patients, combined with conventional pathology, especially when choosing among chemotherapy, immunotherapy and other potential therapeutic measures. Whereas the collection of retrospective clinical data and incomplete treatment data of patients from most of the present published studies might lead to low repeatability and effectiveness, it was necessary to reach a consensus based on well-designed prospective studies to translate this strategy into reliable measures to improve the therapeutic effect in BC patients.

\section{Abbreviations}

BC: bladder cancer; PRISMA: Preferred Reporting Items for Systematic Review and Meta-Analysis; PROSPERO: prospective register of systematic reviews; RCT: randomized controlled trial; CC: consensus clusters; GU: genomically unstable; SCCL: squamous cell cancer-like; Uro: urobasal; OR: odds ratio; 95\% Cl: 95\% confidence interval; RoB: risk of bias; NOS: Newcastle-Ottawa Scale; IHC: Immunohistochemistry; GE: gene expression; OS: Overall survival; DSS: diseasespecific survival; CSM: cancer-specific mortality;

\section{Declarations}

Ethics approval and consent to participate: This study is based on a systematic review and meta-analysis and therefore has not been conducted on human or animal subjects. No informed consent was obtained because the study was not carried out on human subjects.

Consent for publication: Not applicable.

Availability of data and materials: All data generated or analysed during this study are included in this published article and referenced articles are listed in the References section.

Competing interests: The authors declare that they have no conflicts of interest that might be relevant to the contents of this manuscript.

FundingDThis research was funded with Kuanren Talents Program (KY2019Y026『of Chongqing Medical University and National Natural Science Foundation of China (81803057).

Authors' contributions: SD Wang, XY Yuan, JM Zhao and BS Zheng collected and processed the data from the studies, and performed data analysis. SD Wang and ZJ Shen drafted the manuscript and designed the figures. SD Wang, CG Ge and JY Zhang contributed to the writing of the manuscript. CG Ge and JY Zhang conceptualized the research, supervised the work, and contributed to the editing and wiritng of the final manuscript. All authors read and approved the final manuscript.

Acknowledgements: The authors would like to thank all working group members for their contribution to this study and express their heartfelt gratitude to their mentor and research team.

\section{References}

1. Soukup V, Capoun O, Cohen D, et.al. Risk Stratification Tools and Prognostic Models in Non-muscle-invasive Bladder Cancer: A Critical Assessment from the European Association of Urology Non-muscle-invasive Bladder Cancer Guidelines Panel. Eur Urol Focus. 2020;6(3):479489.https://doi.org/10.1016/j.euf.2018.11.005

2. Kardoust PM, Enikeev D, Glybochko PV, et.al. Prognostic value of T1 substaging on oncological outcomes in patients with non-muscle-invasive bladder urothelial carcinoma: a systematic literature review and meta-analysis. World J Urol. 2020;38(6):1437-1449.https://doi.org/10.1007/s00345-019-02936-y

3. Rey-Cardenas M, Guerrero-Ramos F, Gomez DLLA, et.al. Recent advances in neoadjuvant immunotherapy for urothelial bladder cancer: What to expect in the near future. Cancer Treat Rev. 2021;93:102142.https://doi.org/10.1016/j.ctrv.2020.102142

4. Takemoto K, Teishima J, Kohada Y, et.al. The Impact of Histological Variant on Oncological Outcomes in Patients With Urothelial Carcinoma of the Bladder Treated With Radical Cystectomy. Anticancer Res. 2020;40(8):4787-4793.https://doi.org/10.21873/anticanres.14481

5. Kamoun A, de Reyniès A, Allory Y, et.al. A Consensus Molecular Classification of Muscle-invasive Bladder Cancer. Eur Urol. 2020;77(4):420433.https://doi.org/10.1016/j.eururo.2019.09.006

6. Mo Q, Nikolos F, Chen F, et.al. Prognostic Power of a Tumor Differentiation Gene Signature for Bladder Urothelial Carcinomas. J Natl Cancer Inst. 2018;110(5):448-459.https://doi.org/10.1093/jnci/djx243

7. Choi W, Porten S, Kim S, et.al. Identification of Distinct Basal and Luminal Subtypes of Muscle-Invasive Bladder Cancer with Different Sensitivities to Frontline Chemotherapy. Cancer Cell. 2014;25(2):152-165.https://doi.org/10.1016/j.ccr.2014.01.009

8. Robertson AG, Kim J, Al-Ahmadie H, et.al. Comprehensive Molecular Characterization of Muscle-Invasive Bladder Cancer. Cell. 2018;174(4):1033.https://doi.org/10.1016/j.cell.2018.07.036

9. Rebouissou S, Bernard-Pierrot I, de Reynies A, et.al. EGFR as a potential therapeutic target for a subset of muscle-invasive bladder cancers presenting a basal-like phenotype. Sci Trans/ Med. 2014;6(244):244ra91.https://doi.org/10.1126/scitransImed.3008970

Page 5/14 
10. Marzouka N, Eriksson P, Rovira C, et.al. A validation and extended description of the Lund taxonomy for urothelial carcinoma using the TCGA cohort. Sci Rep-Uk. 2018;8(1):3737.https://doi.org/10.1038/s41598-018-22126-x

11. Seiler R, Ashab HAD, Erho N, et.al. Impact of Molecular Subtypes in Muscle-invasive Bladder Cancer on Predicting Response and Survival after Neoadjuvant Chemotherapy. Eur Urol. 2017;72(4):544-554.https://doi.org/10.1016/j.eururo.2017.03.030

12. Liberati A, Altman DG, Tetzlaff J, et.al. The PRISMA statement for reporting systematic reviews and meta-analyses of studies that evaluate healthcare interventions: explanation and elaboration. BMJ. 2009;339:b2700.https://doi.org/10.1136/bmj.b2700

13. Aine M, Eriksson P, Liedberg F, Sjödahl G, Höglund M. Biological determinants of bladder cancer gene expression subtypes. Sci Rep-Uk. 2015;5:10957.https://doi.org/10.1038/srep10957

14. Stang A. Critical evaluation of the Newcastle-Ottawa scale for the assessment of the quality of nonrandomized studies in meta-analyses. Eur J Epidemiol. 2010;25(9):603-5.https://doi.org/10.1007/s10654-010-9491-z

15. Rosenberg JE, Hoffman-Censits J, Powles T, et.al. Atezolizumab in patients with locally advanced and metastatic urothelial carcinoma who have progressed following treatment with platinum-based chemotherapy: a single-arm, multicentre, phase 2 trial. The Lancet. 2016;387(10031):19091920.https://doi.org/10.1016/S0140-6736(16)00561-4

16. Song B, Kim S, Mun J, et.al. Identification of an immunotherapy-responsive molecular subtype of bladder cancer. Ebiomedicine. 2019;50:238245.https://doi.org/10.1016/j.ebiom.2019.10.058

17. Kim J, Kwiatkowski D, McConkey DJ, et.al. The Cancer Genome Atlas Expression Subtypes Stratify Response to Checkpoint Inhibition in Advanced Urothelial Cancer and Identify a Subset of Patients with High Survival Probability. Eur Urol. 2019;75(6):961964.https://doi.org/10.1016/j.eururo.2019.02.017

18. Efstathiou JA, Mouw KW, Gibb EA, et.al. Impact of Immune and Stromal Infiltration on Outcomes Following Bladder-Sparing Trimodality Therapy for Muscle-Invasive Bladder Cancer. Eur Urol. 2019;76(1):59-68.https://doi.org/10.1016/j.eururo.2019.01.011

19. Tanaka H, Yoshida S, Koga F, et.al. Impact of Immunohistochemistry-Based Subtypes in Muscle-Invasive Bladder Cancer on Response to Chemoradiation Therapy. International Journal of Radiation Oncology Biology*Physics. 2018;102(5):1408-1416.https://doi.org/10.1016/j.ijrobp.2018.06.030

20. Sharma P, Retz M, Siefker-Radtke A, et.al. Nivolumab in metastatic urothelial carcinoma after platinum therapy (CheckMate 275): a multicentre, singlearm, phase 2 trial. The Lancet Oncology. 2017;18(3):312-322.https://doi.org/10.1016/S1470-2045(17)30065-7

21. Seiler R, Ashab HAD, Erho N, et.al. Impact of Molecular Subtypes in Muscle-invasive Bladder Cancer on Predicting Response and Survival after Neoadjuvant Chemotherapy. Eur Urol. 2017;72(4):544-554.https://doi.org/10.1016/j.eururo.2017.03.030

22. Jalanko T, de Jong JJ, Gibb EA, Seiler R, Black PC. Genomic Subtyping in Bladder Cancer. Curr Uro/ Rep. 2020;21(2).https://doi.org/10.1007/s11934-0200960-y

23. Choi W, Czerniak B, Ochoa A, et.al. Intrinsic basal and luminal subtypes of muscle-invasive bladder cancer. Nature reviews. Urology. 2014;11(7):400410.https://doi.org/10.1038/nrurol.2014.129

24. Aljabery F, Shabo I, Gimm O, Jahnson S, Olsson H. The expression profile of p14, p53 and p21 in tumour cells is associated with disease-specific survival and the outcome of postoperative chemotherapy treatment in muscle-invasive bladder cancer. Urologic oncology. 2018;36(12):530.e7-

530.e18.https://doi.org/10.1016/j.urolonc.2018.05.025

25. Chen X, Liu M, Meng F, et.al. The long noncoding RNA HIF1A-AS2 facilitates cisplatin resistance in bladder cancer. J Cell Biochem. 2019;120(1):243252.https://doi.org/10.1002/jcb.27327

26. Lee E, Collazo-Lorduy A, Castillo-Martin M, et.al. Identification of microR-106b as a prognostic biomarker of p53-like bladder cancers by ActMiR. Oncogene. 2018;37(44):5858-5872.https://doi.org/10.1038/s41388-018-0367-0

27. Guo CC, Dadhania V, Zhang L, et.al. Gene Expression Profile of the Clinically Aggressive Micropapillary Variant of Bladder Cancer. Eur Urol. 2016;70(4):611-620.https://doi.org/10.1016/j.eururo.2016.02.056

28. Todenhöfer T, Seiler R. Molecular subtypes and response to immunotherapy in bladder cancer patients. Translational Andrology and Urology. 2019;8(S3):S293-S295.https://doi.org/10.21037/tau.2019.06.21

29. Powles T, Durán I, van der Heijden MS, et.al. Atezolizumab versus chemotherapy in patients with platinum-treated locally advanced or metastatic urothelial carcinoma (IMvigor211): a multicentre, open-label, phase 3 randomised controlled trial. The Lancet. 2018;391(10122):748-

757.https://doi.org/10.1016/S0140-6736(17)33297-X

30. Yoshida T, Kates M, Fujita K, Bivalacqua TJ, McConkey DJ. Predictive biomarkers for drug response in bladder cancer. Int J Urol. 2019;26(11):10441053.https://doi.org/10.1111/iju.14082

31. Shariat SF, Gust KM. Immune therapy meets precision medicine. Lancet Oncol. 2017;18(3):271-273.https://doi.org/10.1016/S1470-2045(17)30098-0

\section{Tables}




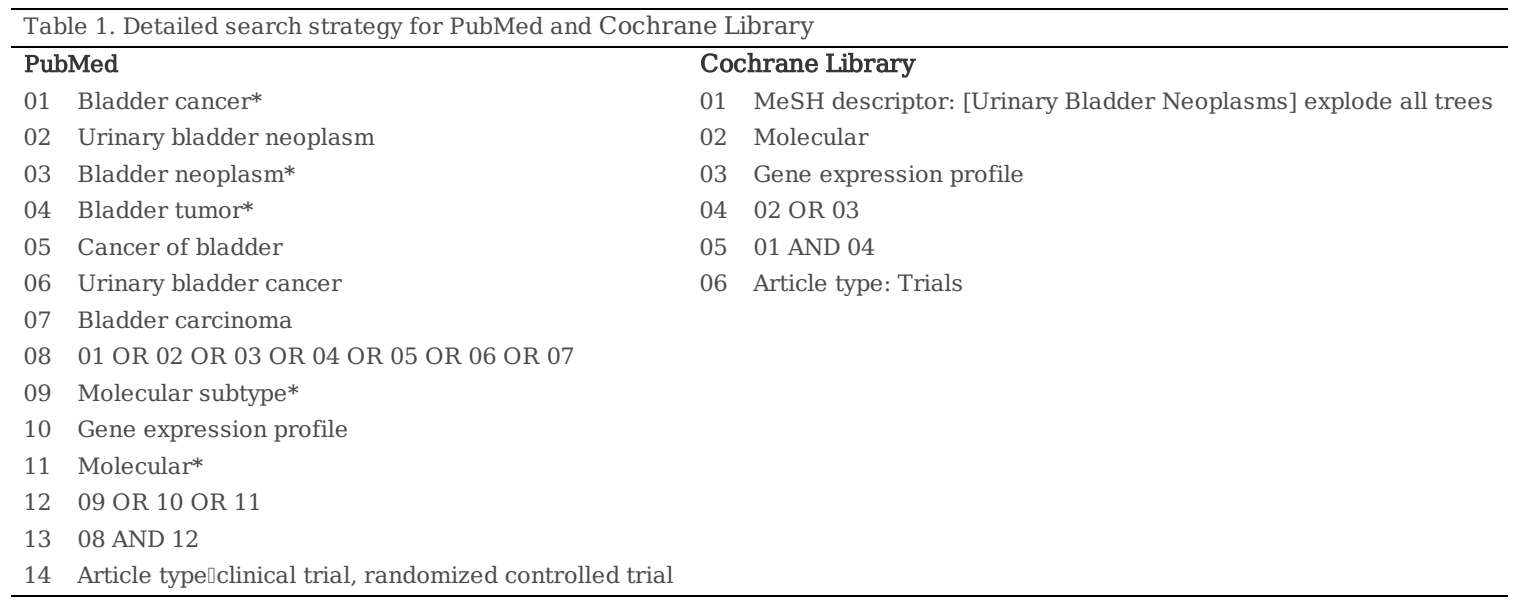

Table 2. Characteristics of included studies

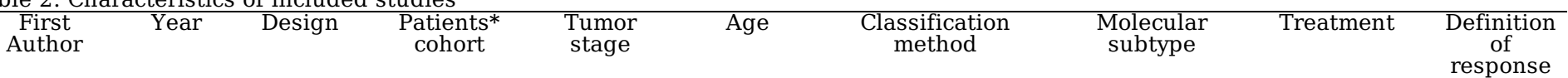

\begin{tabular}{|c|c|c|c|c|c|c|c|c|c|}
\hline Choi 2014 & 2014 & Retrospective & 18 & $\geq \mathrm{cT} 2 \mathrm{NOMO}$ & Mean:68.8 & Gene expression & $\begin{array}{l}\text { Basal(27.8\%), } \\
\text { p53-like(33.3\%), } \\
\text { Luminal(38.9\%) }\end{array}$ & NAC & pT0-1 \\
\hline $\begin{array}{l}\text { Rosenberg } \\
2016\end{array}$ & 2016 & Prospective & 195 & $\begin{array}{l}\mathrm{T} 4 \mathrm{bN} \pm \text { or } \\
\mathrm{T} \pm \mathrm{N} 2-3\end{array}$ & N/A & Gene expression & $\begin{array}{l}\text { TCGA Luminal } \\
\text { cluster I-II(36.9\%, } \\
25.7 \%) \text {, Basal } \\
\text { cluster III- } \\
\text { IV }(19.5 \%, 17.9 \%)\end{array}$ & Atezolizumab & $\begin{array}{l}\text { CR, PR, SD, } \\
\text { PD }\end{array}$ \\
\hline Seiler 2017 & 2017 & Retrospective & 269 & cT2-4N \pm M0 & Mean:61 & Gene expression & $\begin{array}{l}\text { Claudin- } \\
\text { low(21.2\%), } \\
\text { Basal(25.3\%), } \\
\text { Luminal- } \\
\text { infiltrated(12.3\%), } \\
\text { Luminal(41.2\%) }\end{array}$ & NAC & $<\mathrm{pT} 2 \mathrm{~N} 0$ \\
\hline Sharma 2017 & 2017 & Prospective & 177 & $\begin{array}{l}\text { Metastatic } \\
\text { BC with prior } \\
\text { chemotherapy }\end{array}$ & Median:66 & Gene expression & $\begin{array}{l}\text { Luminal 1(37.3\%), } \\
\text { Luminal 2(31.1\%), } \\
\text { Basal 1(13.0\%), } \\
\text { Basal 2(18.6\%) }\end{array}$ & Nivolumab & $\begin{array}{l}\text { CR, PR, SD, } \\
\text { PD }\end{array}$ \\
\hline Tanaka 2018 & 2018 & Retrospective & 118 & cT2-4NOM0 & Median:70 & Immunohistochemistry & $\begin{array}{l}\text { Uro(22.0\%), } \\
\text { GU(51.7\%), } \\
\text { SCCL(26.3\%) }\end{array}$ & Chemoradiation & $\begin{array}{l}\text { CR, PR, SD, } \\
\text { PD }\end{array}$ \\
\hline Efstathiou 2019 & 2019 & Retrospective & 223 & cT2-4aNOM0 & Median:70.2 & Gene expression & $\begin{array}{l}\text { Luminal (36.3\%), } \\
\text { Luminal- } \\
\text { infiltrated } \\
\text { (17.0\%), Basal } \\
\text { (26.5\%), Claudin- } \\
\text { low (20.2\%) }\end{array}$ & NAC & pT0 \\
\hline Kim 2019 & 2019 & Retrospective & 298 & $\begin{array}{l}\text { Platinum } \\
\text { refractory or } \\
\text { cisplatin- } \\
\text { ineligible BC }\end{array}$ & $\mathrm{N} / \mathrm{A}$ & Gene expression & $\begin{array}{l}\text { TCGA(2017) } \\
\text { Basal(32\%), } \\
\text { Luminal(11\%), } \\
\text { Luminal- } \\
\text { infiltrated(21\%), } \\
\text { Luminal- } \\
\text { papillary(33\%), } \\
\text { Neuronal(3\%) }\end{array}$ & Atezolizumab & $\begin{array}{l}\text { CR, PR, SD, } \\
\text { PD }\end{array}$ \\
\hline Song 2019 & 2019 & Retrospective & 165 & $\begin{array}{l}\text { Platinum } \\
\text { refractory or } \\
\text { cisplatin- } \\
\text { ineligible BC }\end{array}$ & N/A & Gene expression & $\begin{array}{l}\text { Class 1-4(29.7\%, } \\
26.7 \%, 226.1 \% \text {, } \\
17.5 \%)\end{array}$ & Atezolizumab & $\begin{array}{l}\text { CR, PR, SD, } \\
\text { PD }\end{array}$ \\
\hline
\end{tabular}

*Patients with specific molecular subtype. NAC=neo-adjuvant chemotherapy; $\mathrm{RC}=$ radical cystectomy; NS= nonsignificant; $\mathrm{N} / \mathrm{A}=$ not available; ( $\mathrm{CR}=$ complete response; $\mathrm{PR}=$ partial response; $\mathrm{SD}=$ stable disease; $\mathrm{PD}=$ progressive disease; $\mathrm{Uro}=$ urobasal; $\mathrm{GU}=\mathrm{genomically}$ unstable; $\mathrm{SCCL}=\mathrm{SC}$ $\mathrm{DSS}=$ disease-specific survival; $\mathrm{BC}=$ bladder cancer 


\begin{tabular}{|c|c|c|c|c|c|c|c|c|c|}
\hline Study & $\mathrm{A}$ & B & $\mathrm{C}$ & $\mathrm{D}$ & $\mathrm{E}$ & $\mathrm{F}$ & $\mathrm{G}$ & $\mathrm{H}$ & Total \\
\hline Choi 2014 & 0 & 0 & 1 & 1 & 2 & 1 & 1 & 1 & 7 \\
\hline Seiler 2017 & 1 & 1 & 1 & 1 & 2 & 1 & 1 & 1 & 9 \\
\hline Tanaka 2018 & 1 & 1 & 1 & 1 & 1 & 1 & 1 & 1 & 8 \\
\hline Efstathiou 2019 & 1 & 1 & 1 & 1 & 1 & 1 & 1 & 1 & 8 \\
\hline Kim 2019 & 1 & 0 & 1 & 1 & 1 & 0 & 1 & 1 & 6 \\
\hline Song 2019 & 1 & 1 & 1 & 1 & 1 & 1 & 1 & 1 & 8 \\
\hline
\end{tabular}

$\mathrm{A}=$ Is the case definition adequate? $\mathrm{B}=$ Representativeness of the cases. $\mathrm{C}=$ Selection of Controls. $\mathrm{D}=\mathrm{Definition}$ of Controls. E= Comparability of cases and controls on the basis of the design or analysis. F= Ascertainment of exposure. $\mathrm{G}=$ Same method of ascertainment for cases and controls. H= Non-Response rate.

\section{Figures}

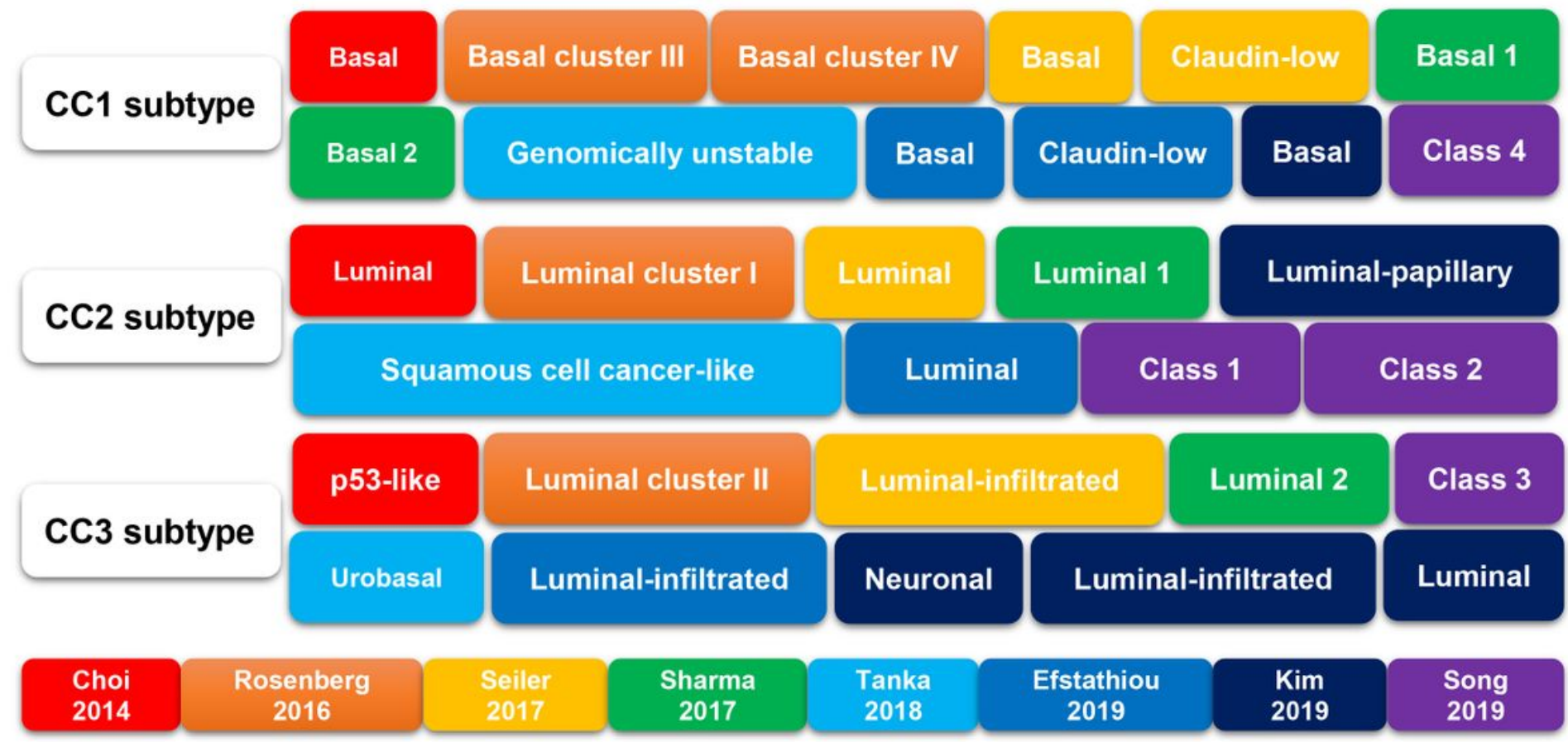

Figure 1

Interrelations between three subtypes $(\mathrm{CC} 1, \mathrm{CC} 2, \mathrm{CC} 3)$ in this meta-analysis and the molecular subtypes in included studies. 
3340 studies identified through PubMed searching.
22 studies identified through Cochrane Library searching.
11 additional records identified through other sources: Scopus, EMBASE, MEDLINE, Web of Science, CBM and $\mathrm{CNKI}$.

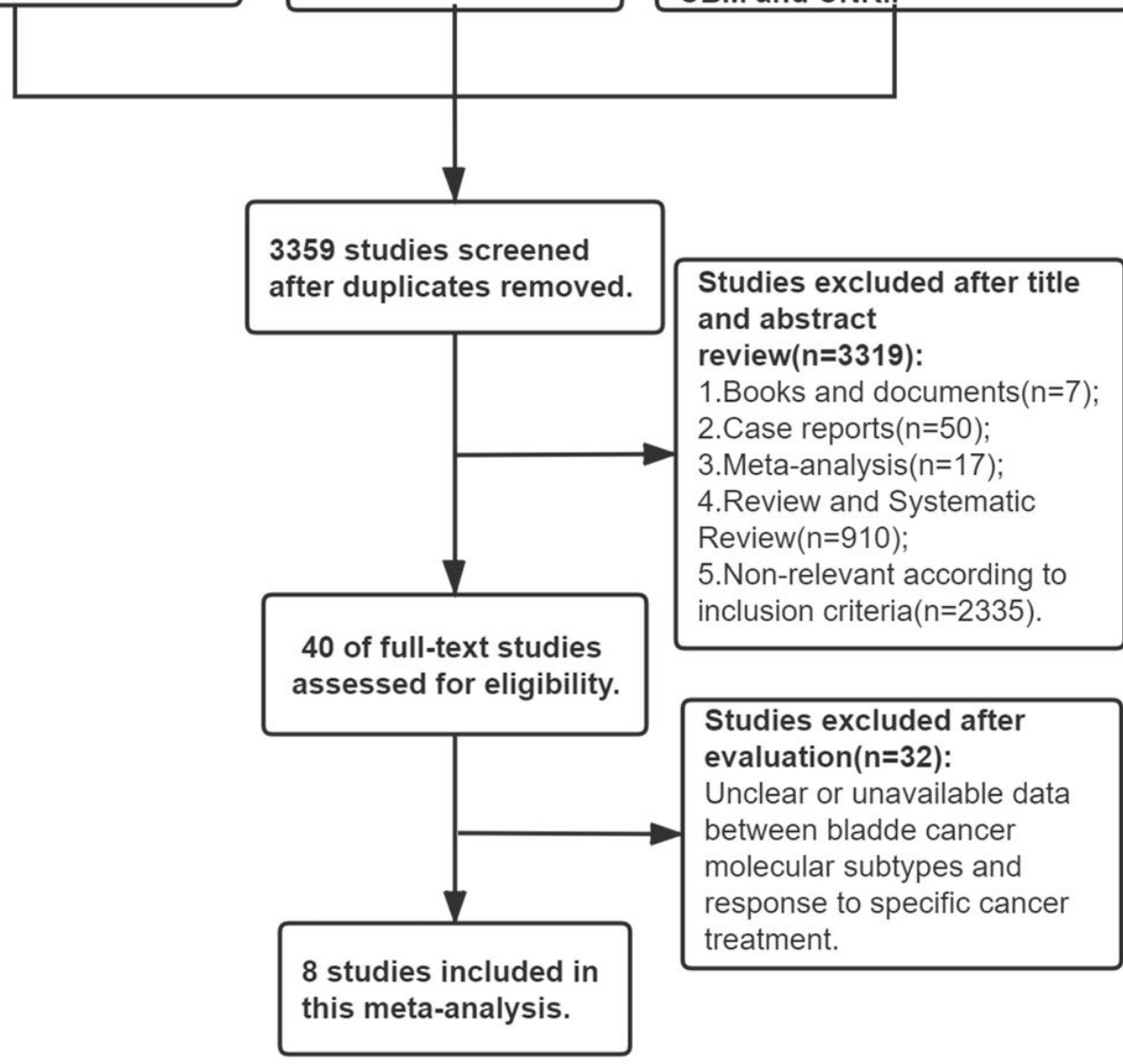

Figure 2

PRISMA flow chart for article selection process to analyze the association between molecular subtypes and therapeutic response in patients with bladder cancer. 


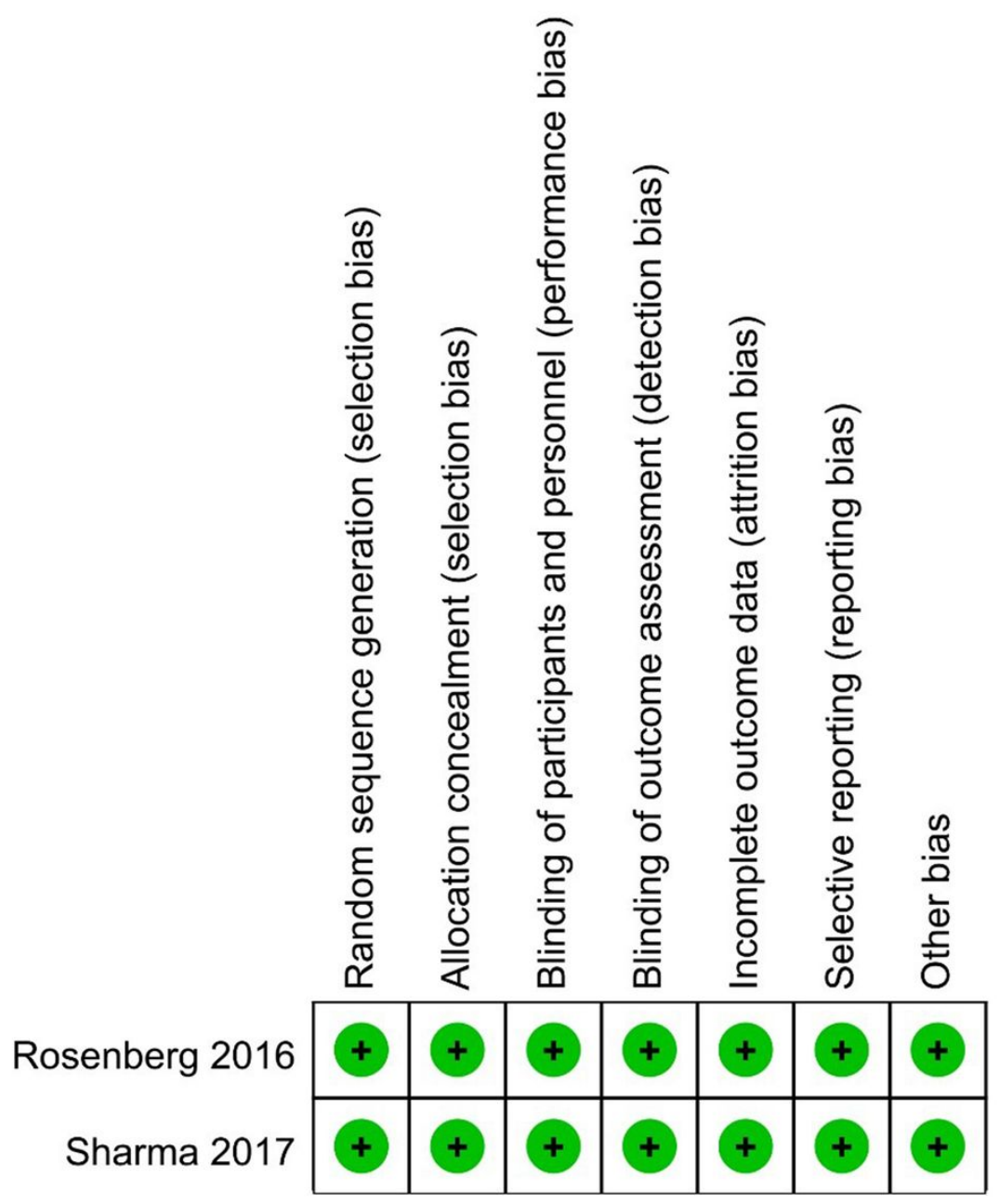

Figure 3

Risk of bias assessment of included RCTs studies. 

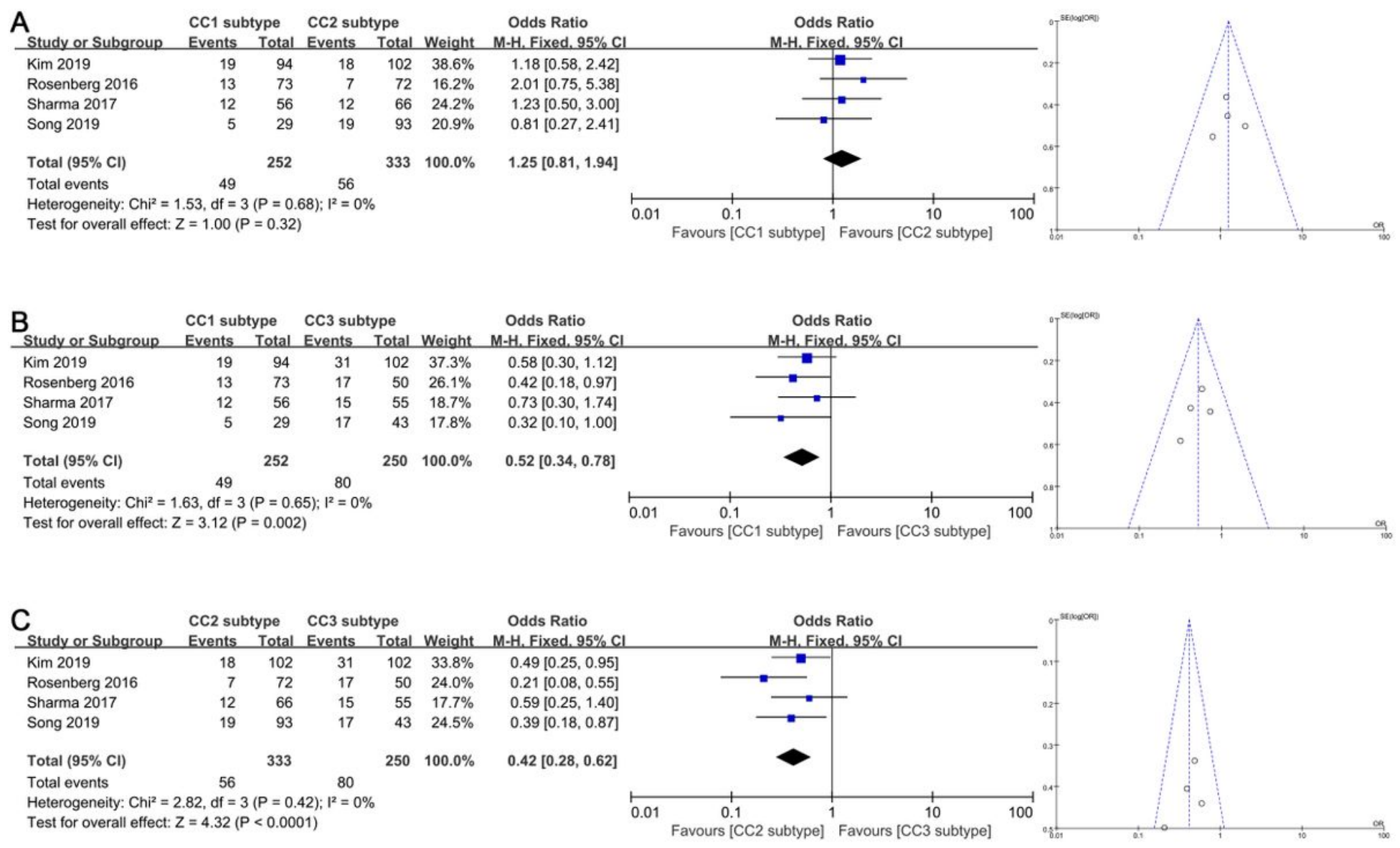

\section{Figure 4}

Forest plots and funnel plots of studies investigating the association of CC1, CC2 and CC3 molecular subtype with response to immunotherapy. CC1 subtype (basal, basal cluster III-IV, claudin-low, basal 1 and 2, class4, genomically unstable); CC2 subtype (luminal, luminal cluster I, luminal 1, luminal-papillary, class 1 and 2, and squamous cell cancer-like); CC3 subtype (p53-like, luminal cluster II, luminal, luminal-infiltrated, luminal 2, class 3, neuronal, and urobasal). 


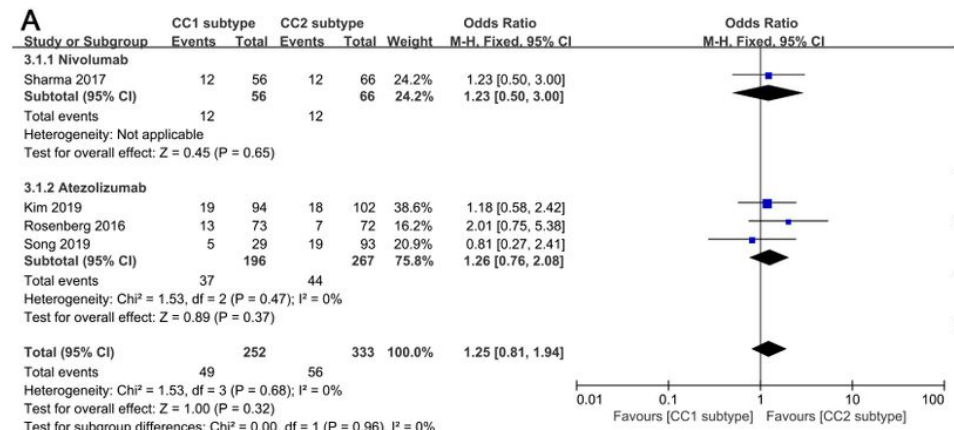

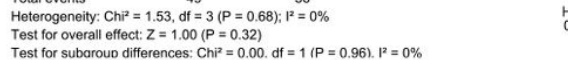

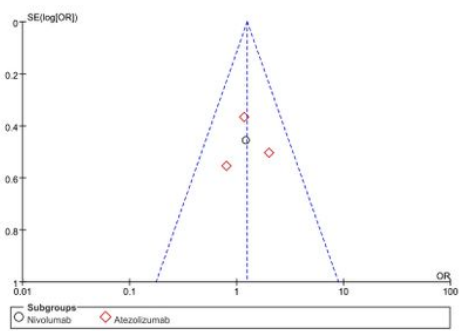

B cc1 subtype CC3 subtype Odds Ratio $\begin{array}{llll}\text { Study or Subgroup } & \text { Events Total Events Total Weight } & \text { Odds Ratio } & \text { Odds Ratio } \\ \text { M.H. Fixed, } 95 \% \mathrm{Cl} & \text { M-H. Fixed. } 95 \% \mathrm{C}\end{array}$ $\begin{array}{lllllll}\text { 3.2.1 Nivolumab } & & & & & & \\ \text { Sharma 2017 } & 12 & 56 & 15 & 55 & 18.7 \% & 0.73[0.30,1.74] \\ \text { Subtotal }(95 \% \mathrm{Cl}) & & 56 & & \mathbf{5 5} & \mathbf{1 8 . 7 \%} & \mathbf{0 . 7 3}[0.30,1.74]\end{array}$ Heterogeneity: Not applicable
Test for overall effect: $Z=0.72(P=0.47)$

3.2.2 Atezolizumab

Kim 2019

Rosenberg 2016
Song 2019

Total events

Heterogeneity: Chi. $=0.91$, df $=2(P=0.64) ; 1^{2}=0 \%$
Test for overall effect: $Z=3.14(P=0.002)$

Total $(95 \% \mathrm{Cl}$

Total events
Heterogeneity: $C i^{2}=1.63$, df $=3(P=0.65): l^{2}=0$

Test for overall effect: $Z=3.12(P=0.002$
Test for subarouo differences: $C \mathrm{Ch}^{2}=0.74$
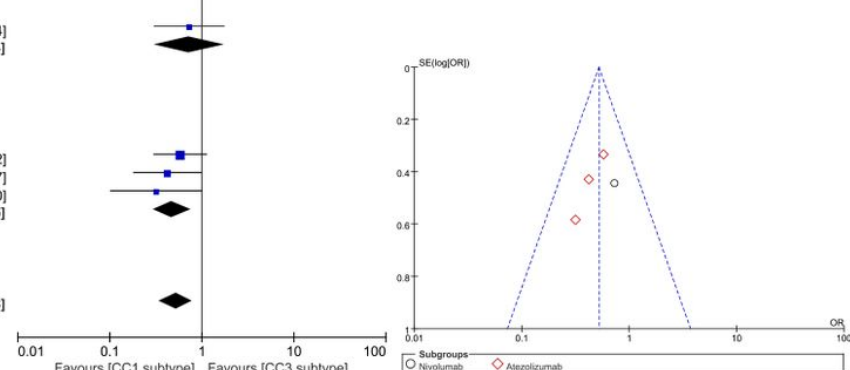

$\begin{array}{llll}\text { CC2 subtype CC3 subtype } & \text { Odds Ratio } \\ \text { Study or Subgroup } & \begin{array}{l}\text { Events Total Events Total Weight } \\ \text { M-H. Fixed. } 95 \%\end{array}\end{array}$

$\begin{array}{lllllllll}\text { Sharma } 2017 & 12 & 66 & 15 & 55 & 177 \% & 0591025: 1400\end{array}$

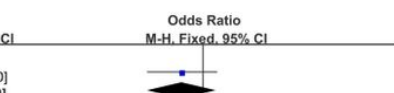

Total events

$\begin{array}{lllll}12 & 66 & 55 & 17.7 \% & 0.59[0.25,1.40 \\ 12 & & 55 & 17.7 \% & 0.59[0.25,1.40\end{array}$

Heterogeneity: Not applicable
Test for overall effect: $Z=1.19(P=0.23)$

Kim 2019

Kim 2019

Song 2019
Subtotal $(95 \% \mathrm{Cl})$

Total events

Test for ove

Total $(95 \% \mathrm{Cl})$

Total events

$\begin{array}{rrrrrr}18 & 102 & 31 & 102 & 33.8 \% & 0.49[0.25,0.95]\end{array}$

17
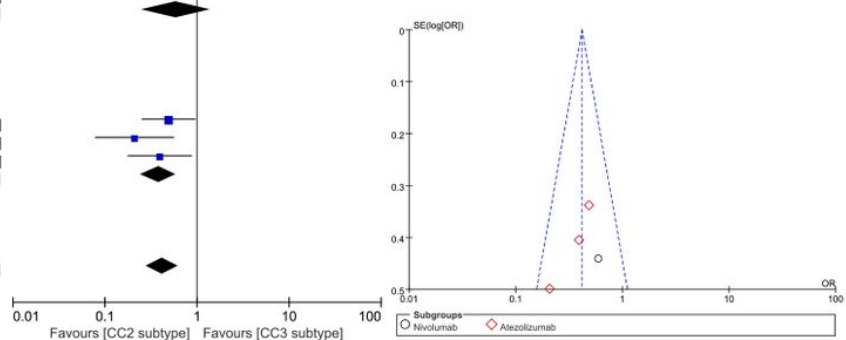

Test for suberoun differences: $C^{2} \mathrm{i}^{2}=0.011 \mathrm{df}=1(\mathrm{P}=0.37) \mathrm{P}=0 \%$ $0.38[0.24,0.59]$

\section{Figure 5}

Comparison on response to cancer treatment between $\mathrm{CC} 1, \mathrm{CC} 2$ and $\mathrm{CC} 3$ subtypes after subgroup analysis stratified by immunotherapeutic regimens. 

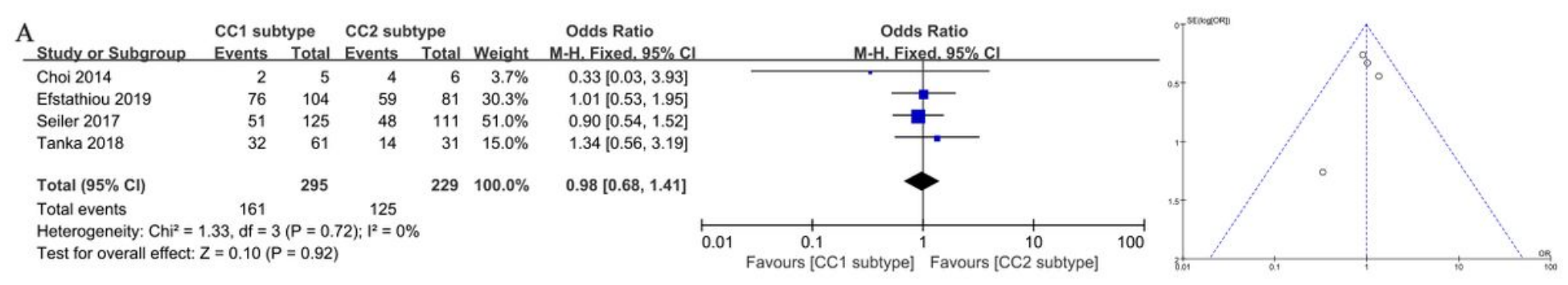

B

CC1 subtype CC3 subtype Odds Ratio Study or Subgroup Events Total Events Total Weight M-H. Fixed. 95\% Cl $\left.\begin{array}{lllllll}\text { Choi } 2014 & 2 & 5 & 0 & 7 & 1.2 \% & 10.71 \\ {[0.40,287.83}\end{array}\right]$ Efstathiou 2019 Seiler 2017 Tanka 2018

Total $(95 \% \mathrm{Cl})$

$\begin{array}{llc}\text { Total events } & 161 & 38 \\ \text { Heterogeneity: } \mathrm{Chi}^{2}=5.14, \mathrm{df}=3(\mathrm{P}=0.16) ; 1^{2}=42 \%\end{array}$

Test for overall effect: $Z=3.25(P=0.001)$
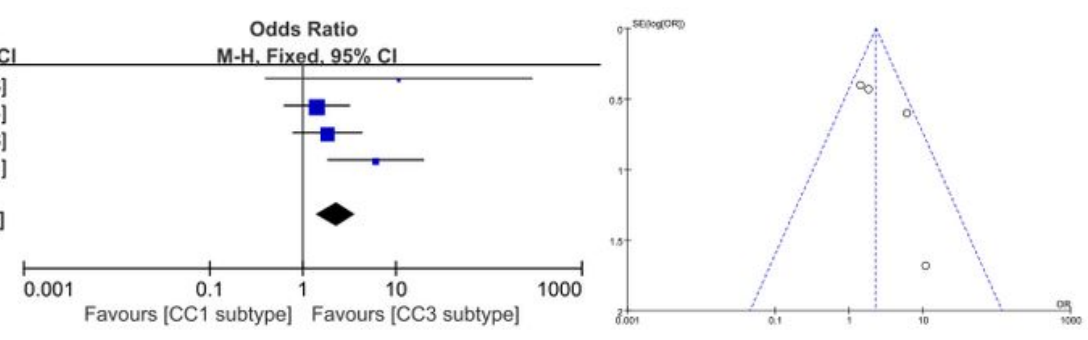

$\mathrm{C}_{\mathrm{S}}$

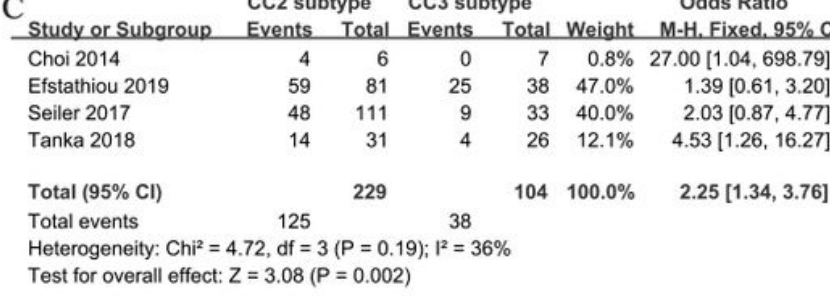

Test for overall effect: $Z=3.08(P=0.002)$
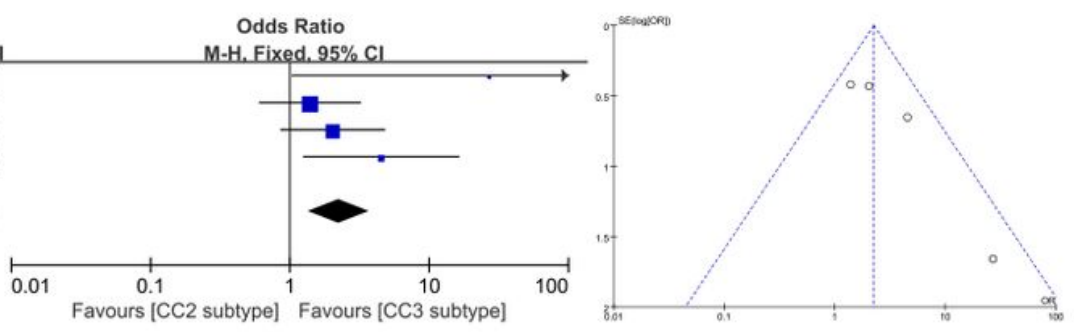

\section{Figure 6}

Forest plots and funnel plots of studies investigating the association of CC1, CC2 and CC3 molecular subtype with response to chemotherapy. 

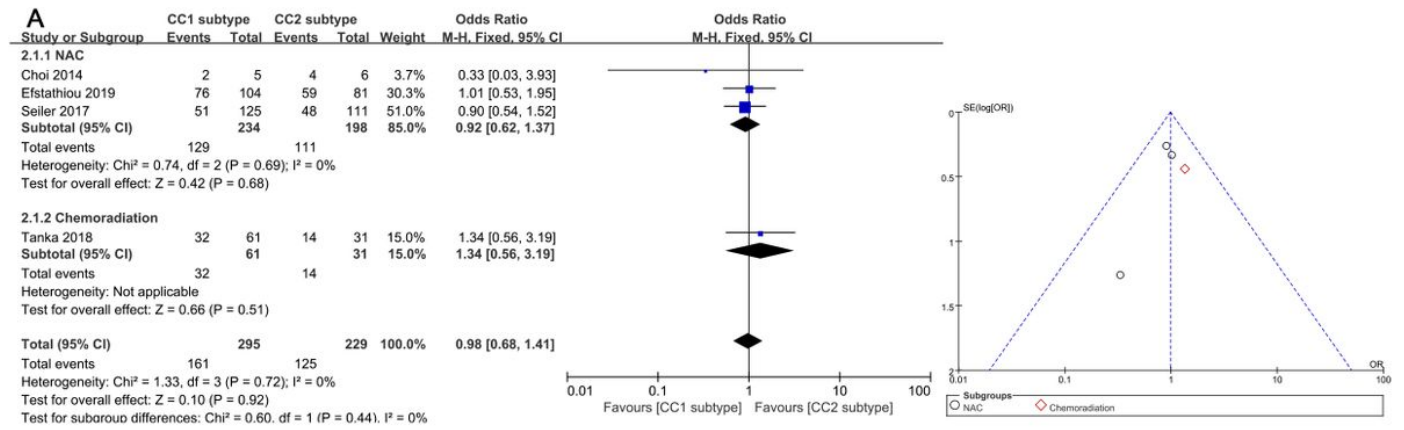

Test for subaroun differences: $\mathrm{Ch}^{2}=0.60 . \mathrm{df}=1(\mathrm{P}=0.44) . \mathrm{P}^{\mathrm{P}}=0 \%$

B cc1 subtype cc3 subtype Odds Ratio
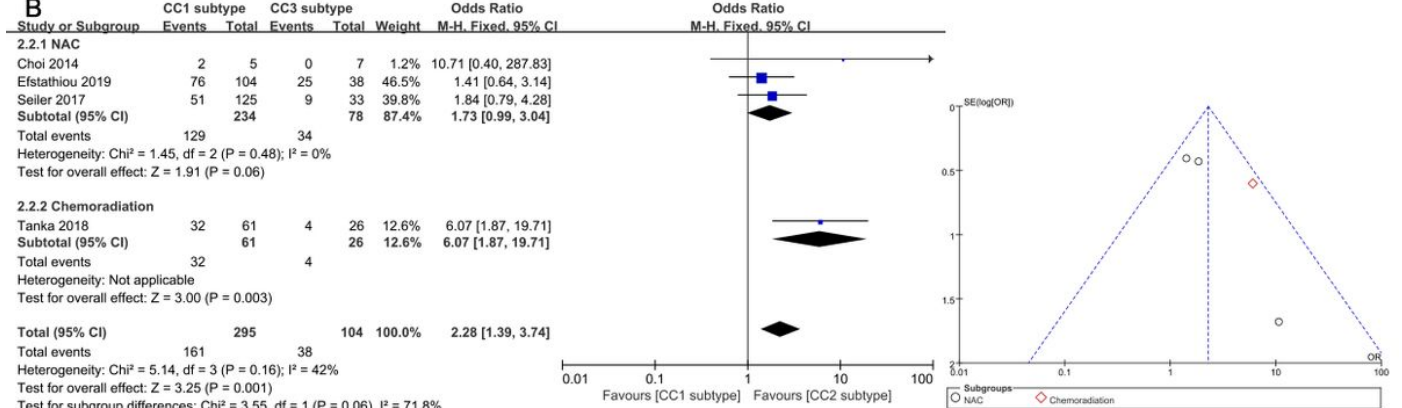

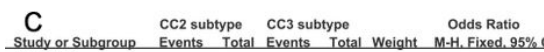
2.3.1 NAC $\begin{array}{lrrrrrr}\text { Choi 2014 } & 4 & 6 & 0 & 7 & 0.8 \% & 27.00[1.04,698.79] \\ \text { Ef́stathiou } 2019 & 59 & 81 & 25 & 38 & 47.0 \% & 139[1961,320]\end{array}$ $\begin{array}{lrrrrrr}\text { Efstathiou 2019 } & 59 & 81 & 25 & 38 & 47.0 \% & 1.39[0.61,3.20] \\ \text { Seiler 2017 } & 48 & 111 & 9 & 33 & 40.0 \% & 203[0.87,4.77]\end{array}$ $\begin{array}{llllllll}\text { Seiler } 2017 & 48 & 111 & 9 & 33 & 40.0 \% & 2.03[0.87,4.77] \\ \text { Subtotal }(95 \% \mathrm{Cl}) & & 198 & & 78 & 87.9 \% & 1.93[1.09,3.41]\end{array}$ Total events

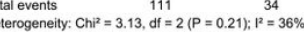
est for overall effect: $Z=2.27(P=0.02)$

2.3.2 Chemoradiatio $\begin{array}{lllllll}\text { Tanka 2018 } & 14 & 31 & 4 & 26 & 12.1 \% & 4.53[1.26,16.27] \\ \text { Subtotal (95\% Cl) } & & 31 & & 26 & 12.1 \% & 4.53[1.26,16.27]\end{array}$ Heterogeneity: Not applicab 229 $3(P=0.19) ; i^{2}=36 \%$

Heterogeneity: $\mathrm{Ch}^{2}=4.72, \mathrm{df}=3(\mathrm{P}=0.19)$

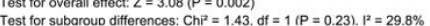

$104 \quad 100.0 \% \quad 2.25[1.34,3.76]$
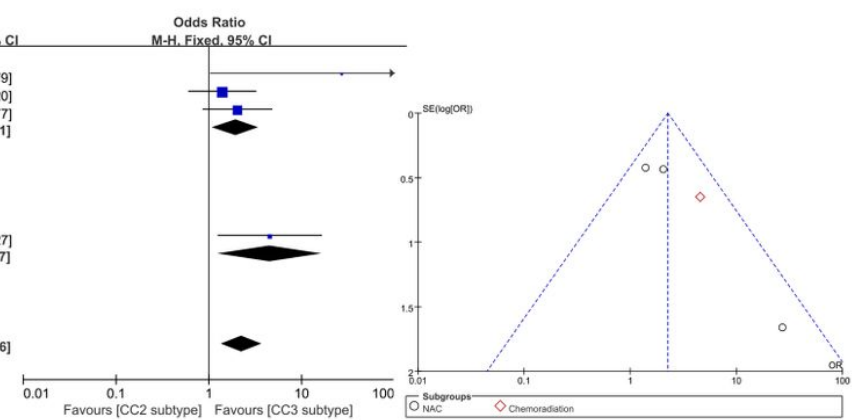

\section{Figure 7}

Comparison on response to cancer treatment between $\mathrm{CC} 1, \mathrm{CC} 2$ and $\mathrm{CC} 3$ subtypes after subgroup analysis stratified by chemotherapeutic regimens. 